\title{
Vadja pere- ja muud omandimärgid
}

\section{Tatjana Jefimova}

Peremärgid on tuntud peaaegu kogu maailmas. Kihnu peremärkide uurija Theodor Saare andmeil on soome-ugri rahvastest neid tarvitanud liivlased, eestlased, soomlased, saamid, mordvalased ja marid (Saar 1998: 29). Vadjalasi ta ei nimetanud.

Peremärgi mõistet kohtasin esmakordselt D. Zolotarjovi 1926. aasta ekspeditsiooni tulemustega tutvudes (Zolotarjov 1927: 143, 148), kus ta loetleb vadja külades, sh Alam-Luuditsas huvi pakkunud tõiku ja mainib ka peremärkide (merkat) kasutamist heinamaade jagamisel. Ta seletab: Peremärgid tehakse teopulkadele, loosipulkadele, tööriistadele ja igapäevastele tarbeesemetele.

Teema hakkas mind väga huvitama ja pöördusin selgituse saamiseks Luuditsa (vene keeles Lužitsõ) - sellise nimetuse sai küla pärast Alam-Luuditsa ja Liivtšülä (Peski) liitmist - vanima elaniku, 1906. aastal sündinud Anna Judina poole. Ta jutustas, et tõepoolest oli enne Teist maailmasõda igal perel oma märk ning ta meenutas neist mõnda (vt tabel 1).

Tähelepanu äratab tõik, et järgmise põlvkonna käes peremärk muutus: isa peremärgile lisati mingi uus element (kriips, ring). Tavaliselt päris noorim poeg, kes jäi elama vanemate majja ja hooldas neid surmani, isa peremärgi (3-5). A. Judina ei mäletanud igakord peremärgi omanikku, kuid selle arenguloogika põhjal suutis meelde tuletada, et E-tähe kujuline peremärk oli Nesterovidel, kuid kaar ja ringikesega kaar (13 ja 14) kuulusid vist Mironovitele.

Külaelanikest mäletasid Ivan Agafonov, Zoja Tšernõšova, Anna Trofimova ja Zinaida Putškova hästi oma peremärki. Teistel kulus meenumiseks aega. Sergei Jefimov üritas pool aastat tuletada meelde oma isa peremärki rääkides aina: Ma pean meelde tuletama, isa ju tegi selle alati küttepuudele. Kui küsisin: Milleks ta seda tegi?, siis ta vastas: Metsavahi jaoks, et ta näeks, et oleme kõik korda teinud ja oksad põletanud. Zinaida Saveljeva, kes oli sündinud 1938. aastal Luuditsas, kuid elab nüüd Jõgõperäl (vene keeles Krakolje), selgitas: Raha puude eest maksti ette, metsavaht võttis raielangi vastu, märgi järgi tegi ta kindlaks peremehe, kui kõik oli korras, maksis poole rahast tagasi.

Enamasti meenus peremärk kiiresti neile, kes koos isaga olid käinud metsas puid tegemas või osalenud heinamaatükkide jaga- 


\begin{tabular}{|c|c|c|}
\hline Märk & Omanik & Informant \\
\hline & Omelja Iilja & \multirow{2}{*}{$\begin{array}{l}\text { A. Judina (1906) } \\
\text { Romani lapselaps N. Vittong }\end{array}$} \\
\hline & $\begin{array}{l}\text { Poeg } \\
\text { Omelja Füdera Roman }\end{array}$ & \\
\hline$\square$ & Nesteri Vasja & \multirow{4}{*}{$\begin{array}{l}\text { Vasja pojatütar } \\
\text { A. Judina (1906) }\end{array}$} \\
\hline$\square$ & $\begin{array}{l}\text { Vasja pojanaine } \\
\text { Nesterova Ogru }\end{array}$ & \\
\hline[ & $\begin{array}{l}\text { Nesteri pojapoeg } \\
\text { Kirilla Ondre }\end{array}$ & \\
\hline$E$ & $\begin{array}{l}\text { Nesteri pojapoeg } \\
\text { Kirilla Fedja? }\end{array}$ & \\
\hline t & Savvo Vasja & Tütar Z. V. Tšernõšova (1932) \\
\hline 8 & Jaakko Semon & Poeg P. S. Antonov (1923) \\
\hline \V & Agafona Miša & Poeg I. M. Agafonov (1932) \\
\hline$\varepsilon$ & Luka Isakka & \multirow{2}{*}{$\begin{array}{l}\text { A. Judina, Stepani lapselapsed } \\
\text { V. M. Lukin (1931) } \\
\text { ja N. M. Lukin (1937) }\end{array}$} \\
\hline 1 & Poeg Luka Stepan & \\
\hline$\theta$ & Nikon Kostja & Poeg S. K. Jefimov (1954) \\
\hline$\cap$ & Mironovid? & \multirow[t]{2}{*}{ A. Judina } \\
\hline م & Mironovid? & \\
\hline$\pi$ & $\begin{array}{l}\text { Natol Vanka } \\
\text { (Mihhaili poeg) }\end{array}$ & A. Judina \\
\hline$H$ & Mosse Jaakko & Tütar Z. J. Putškova \\
\hline
\end{tabular}

Tabel 1. Vadja peremärke Teise maailmasõjaeelsest ajast. 
misel. Just viimasel puhul kasutati tahutud vaiakesi loosimiseks, küttepuude tegemisel kanti neile peremärk. Küttepuudele tehtud märke mäletasid peale eespool mainitute veel A. Judina, I. Agafonov ja Z. Putškova. A. Judina teatel kaevati mõnikord peremärk heinamaal labidaga maasse. 1932. aastal sündinud I. Agafonovi andmeil tehti peremärke kõigile hoonetele, lina ropsimise riistale ja pesurullile (rulla-puu). V. Lukin mäletas märki kuuri seinal ja võrgukäbadel, Z. Tšernõšova kartulikottide ja R. Vittong atrade märgistamist. N. Lukinile (sündinud 1937) meenus nende peremärk isegi foto tagaküljel. Peremärke joonistati söega, nikerdati noaga, tehti värviga.

Praegu on raske öelda, kuivõrd kasutati peremärke pärast Teist maailmasõda. Ivan Agafonov väitis, et niikaua, kuni tegin küttepuid, tegin kogu aja märgid peale. Võib arvata, et viimased peremärgid tehti 1970ndate aastate alguses. Kahjuks ei mäleta enamik enam oma peremärki ja selle nimetuski on täielikult ununenud. Panin tähele, et neid vestluse käigus kas üldse ei nimetatudki või korrati minu küsimuses sisalduvaid sõnu znak ja metka 'märk; märgis'. ${ }^{1}$

Peremärkide kasutamise kohta leidub teateid vadja keele sõnastikes:"2 see õli taloo merkki, see õli itšiine 'see oli talumärk, see oli põline' (VKS I 311); jõka talol õli oma merkki 'igal talul oli oma märk' (mõlemad näited Liivtšüläst); jõkaizõl õli õma merkki, arval, jõka talol 'igaühel oli oma märk liisupulgal, igal talul' (Matti), võrkkoil ôltii pullod, tohossa tehtü, siiz neis pulloiz ôltii merkid, meijee taloz õli kane mokom merkki [nool üles] niku ankkuri 'võrkudel olid käbad, tohust tehtud, siis neil käbadel olid märgid, meie talus oli niisugune märk nagu ankur's (VKS III 305). Vadja keele kukkuzi murdest ${ }^{4}$ on talletatud järgmine teade: mejje saraa merkill on kolt pükälää 'meie sarase märgil on kolm pügalat' (IMS 281, 403).

Vadja peremärkide tarvitamise kohta saab lisa 1942. aastal korraldatud vadja ekspeditsiooni ülevaatest (Talve 1981: 2.2.2, 2.2.3; joonis 27). Matti külas olevat liisupulkadele tehtud tavaliselt juhuslikke märke, ent keelejuht Pjotr Baranovil (tollal 42-aastane) oli kasutusel siiski kindel märk - pulga ümber lõigatud ring.

Kukkuzis loositi mets igal aastal uuesti, kusjuures iga langi piirile seati vai, millesse oli lõigatud kummagi talu peremärk. Kui talust pärines kaks venda, kes olid omaette elama asunud, siis tegi teine neist samasuguse peremärgi liisupulga teise otsa. Selles funktsioonis kasutati ka kriipsu pulga keskkohal, ristikest või nikerdati vaia ots sakiliseks (rupsikodjeegaa tehtü). 
Kattila Peenõtsas kasutati peremärkidel üht ja kaht ja poolt ringi, kusjuures ühte ja sama märki kasutati nii heinamaatüki piiritikkudel kui ka liisupulkadel. Kukkuzis oli 1942. aasta teate põhjal kasutusel juba piiritähiste ja liisupulkade nummerdamine.

Tuntud keelejuht Kostja Leontjev on jutustanud 1971. aastal, et peremärk (merkki) tehti labida- ja kirvevarrele ning hoonetele: meijee taloz ôli leikattu kahs ruptsaa niku silmäd 'meie majal oli lõigatud kaks täket nagu silmad'. Need olid kaks teineteise kõrval paiknevat horisontaalset joont. Kui loosimisega jagati maatükke, siis iga peremees asetas enda märgistatud puutiku ühte mütsi. Seejärel mütsi raputati. Samas järjekorras nagu puutikud mütsist välja kukkusid, kanti neil leiduvad peremärgid pikale kepile, kuhu mahtusid kogu küla omad (VE XIV, 57-58). Mitmeid seni lähemalt uurimata peremärke võib leida Eesti Rahva Muuseumi kogudes leiduvatel esemetel, näiteks seenekorvil Rajo külast (B 134:24). Otsinguid tuleks jätkata ka Peterburi muuseumides.

Isiklikke esemeid märgistati ka muul viisil. Pruut tikkis kaasavara valmistades tingimata ees- ja isanime esitähed padjapüüridele, pitsääristele, käterätikutele, särkidele ja sarafanidele. Pavel Antonov meenutas, et ta isal oli rikkalikult kaunistatud hõbedane look vene tähtedega $\mathrm{S}$ ja J (Semjon Jakovlevitš). Mul õnnestus näha looka tähtedega T ja P, mida tänini kasutatakse Valentin Iljini majapidamises (vt joonis 1). Millegipärast on sellel tähtede järjekord

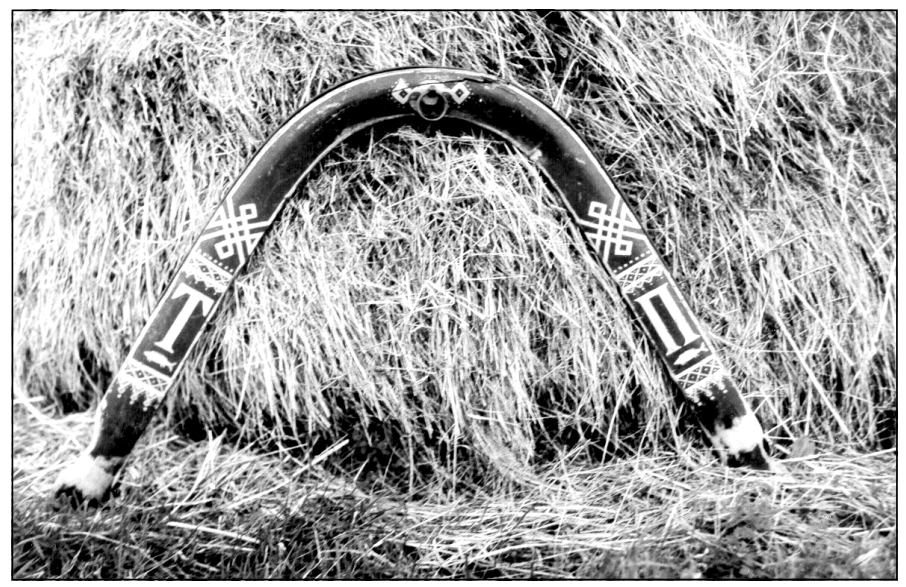

Joonis 1. Initsiaalidega look. 
vastu ootusi, sest peremehe sõnutsi kuulus see kunagi Pjotr Terentjevile.

Tähtedega märgistati ka surnuaeda viidavad ja ristidele riputatavad käterätid. 1903. aastal sündinud Marfa Trofimova jutustas: ...kalmoilla ku meilä avvata pokkoinikka, ni siis meilä tehiä varinikka, kumpa panna rissi $i$ tehäs ühsi bukva i välissä mõnikkalla tehïa koko nimi 'surnuaias, kui meil maetakse surnut, siis meil tehakse rätik, mis pannakse ristile ja tikitakse [= tehakse] üks täht ja teinekord mõnel tehakse kogu nimi' (Lensu 1930: 284).

Märgistati ka koduloomi. Lammastele ja kitsedele seoti kaela värvilised lindikesed või tikitud riideribad. Vadja keele sõnaraamatust leiame järgmise näite: lampaal piäp panna merkki kaglaa, siis tunnõd lampaa 'lambale tuleb panna (tunnus)märk kaela, siis tunned (oma) lamba' (VKS III 305).

Kirjanduses leidub andmeid, et ka vadjalaste naabrid isurid kasutasid peremärke. Vadjaga sarnaseid teateid on näiteks Soikkola poolsaarelt. Heinamaatükkide loosimisel võeti lepaoksi ja joga lebän oksaa tehtii joga taloim merkki 'iga lepaoksasse tehti talumärk'. Samuti leidus neid võrgukäbadel: hela se pidi pääl nigu merkkiin, siz löüsiid ned vergod kättee 'käba, sel pidi siis [olema] peal märk, siis leidsid need võrgud kätte'. Ka lambad märgistati: pannaa lambahille mergit kaglaa, siis tunnedaa omad lampaad 'pannakse lammastele märgid kaela, siis tuntakse ära oma lambad'. Laukaansuust on talletatud vist selles tähenduses sõna tähti: vergon kutooja hoomuksest ku alkaa kutooa, pannoo tähee verkkoo 'võrgukuduja, kui hakkab hommikul kuduma, teeb märgi võrgule' (IMS 18, 55, 306, 616).

Andmed vadja peremärkide kohta on väga napid ja raske on jälgida nende geneesi põlvkonniti, teha kindlaks nende algupärast tähendust ja võimalikku maagilist otstarvet. Ometi arvan, et uuringuid on tarvis jätkata, et panna i-le täpp.

Tõlkinud Enn Ernits

\section{Kommentaarid}

${ }^{1}$ Autor küsitles keelejuhte vene keeles (E. Ernitsa märkus).

2 Tänan sõnaraamatu kõigi köidete kinkijaid Madis Arukaske ja Heinike Heinsood Tartust ning Fenno-Ugria esindajat Tallinnast. 
${ }^{3}$ Vadja ja isuri kirjapilti on mõnevõrra lihtsustatud. Näitelaused on tõlgitud originaalist veidi erinevalt, kusjuures terminile õuemärk on kogu artiklis eelistatud T. Saare sisuliselt täpsemat mõistet peremärk (E. Ernitsa märkus).

${ }^{4}$ Eesti keelde tõlkija on autori nõusolekul võimaluse korral lisanud ainestikku Ilmar Talve (1981) uuringute põhjal ning mõnest vadja ja isuri keele sõnastikust.

\section{Kirjandus}

IMS 1971 = Inkeroismurteiden sanakirja. Nirvi, R. E. (toim). Lexica Societatis Fenno-Ugricae 18. Helsinki.

Lensu, J. 1930. Materialõ po govoram vodi. Zapadnofinski sbornik. Trudõ Komissii po izutšeniju plemennogo sostava naselenija i sopredelnõhh stran 16. Leningrad, lk 201-305.

KMS 1980 = Vatjan kielen Kukkosin murteen sanakirja. Posti, Lauri (koost), Suhonen, Seppo \& Posti, Lauri (toim). Lexica Societatis FennoUgricae 19. Helsinki.

Saar, Theodor 1998. Kihnu raamat. Eesti TA Emakeele Seltsi toimetised 68. Tallinn.

Zolotarjov, D. 1927. U ižor: Ekspeditsionnõje vpetšatlenija. Trudõ Leningradskogo Obštšestva izutšenija mestnogo kraja 1. Leningrad, lk 139-148.

Talve, Ilmar 1981. Vatjalaista kansankulttuuria. Suomalais-ugrilaisen seuran toimituksia 179. Helsinki.

VE = Vadja Etnoloogiat. P. Ariste käsikirjaline kogu Eesti Kirjandusmuuseumi Eesti Rahvaluule Arhiivis.

VKS I-IV 1990-2000 = Vadja keele sõnaraamat. Adler, Elna \& Lepik, Merle. Tallinn. 